\title{
EDITORIAL
}

\section{Happy 50th birthday ARDS!}

\author{
Arthur S. Slutsky ${ }^{1,2^{*}}$, Jesús Villar ${ }^{1,3,4}$ and Antonio Pesenti, ${ }^{5,6}$
}

๑) 2016 Springer-Verlag Berlin Heidelberg and ESICM

Although the condition now known as the acute respiratory distress syndrome (ARDS) has been recognized since at least the Second World War [1], it was not until the landmark paper of Ashbaugh et al. [2] published on 12 August 1967 that interest in this syndrome really began. From a cohort of 272 patients receiving respiratory support [i.e., oxygen or mechanical ventilation (MV)], they identified 12 who had respiratory distress with tachypnea, refractory hypoxemia, decreased compliance, and bilateral pulmonary infiltrates. Mortality was $58 \%$, with greater survival in five patients managed with PEEP $\left(5-10 \mathrm{cmH}_{2} \mathrm{O}\right)$. Pathology revealed heavy lungs, atelectasis, interstitial and alveolar edema, as well as hyaline membranes-a picture similar to the infant respiratory distress syndrome.

Over the years, several diagnostic schema for ARDS have been proposed, all based on a combination of physiological, clinical, and radiographic parameters. These criteria allow the inclusion of a heterogeneous group of patients, many who likely do not have increased alveolar-capillary permeability or the typical histopathological features of ARDS known as diffuse alveolar damage (DAD). Several patients in the original report would probably not now be considered to have ARDS since fluid overload was an important etiological factor in some patients. Although we have had some progress in defining ARDS [3-5], a much better approach to phenotyping these patients is needed, including identification of specific biomarker(s).

Over the past 50 years, we have developed a welldefined conceptual model of ARDS, characterized pathologically by DAD [6]. DAD is caused by an insult to the pulmonary capillary endothelium and the alveolar epithelium, resulting in increased permeability and subsequent interstitial and protein-rich alveolar edema [7],

\footnotetext{
*Correspondence: slutskya@smh.ca

${ }^{1}$ Keenan Research Center for Biomedical Science, Li Ka Shing Knowledge Institute, St. Michael's Hospital, Toronto, ON M5B 1W8, Canada

Full author information is available at the end of the article
}

atelectasis, and structural damage to the lung architecture. Despite our improved understanding of the role of cellular and humoral components of the inflammatory response, we still do not fully understand the importance of neutrophils, alveolar macrophages, platelets, the complement system, and inflammatory mediators in the precise sequence of events leading to ARDS. The coexistence of unresolved infection and extrapulmonary organ failure are major risk factors for fatal outcome. Eventually, the perpetuation of lung inflammation evolves into a fibroproliferative phase in which lung fibrosis, capillary thrombosis, and neovascularization take place. Most ARDS non-survivors die from multiple organ dysfunction during this phase.

Despite progress in understanding the molecular/genetic mechanisms underlying ARDS, the major advances in therapy have been largely based on a better understanding of the underlying physiological mechanisms (Fig. 1). There is now unequivocal evidence from both experimental and clinical studies that MV can cause or aggravate lung injury $[8,9]$, an entity termed ventilator-induced lung injury (VILI). In many respects the manifestations of VILI resemble those of ARDS with the production of a complex array of inflammatory mediators, resulting in a local and a systemic inflammatory response, so-called biotrauma [10]. This has led to the suggestion that much of ARDS may be an iatrogenic disease, rather than a natural progression of the underlying disease [11]; and VILI may in fact be the cause of DAD as observed on lung pathology.

In the original ARDS description, the X-ray appearance of diffuse pulmonary infiltrates suggested a relatively homogeneous disease process. This paradigm was accepted for many years until the studies by Gattinoni et al. [12] using computerized tomography demonstrated that the disease was heterogeneous, with collapsed and consolidated areas mainly in dependent regions, and healthier-looking units in non-dependent regions. The healthy zone can represent as little as $20 \%$

\section{Springer}




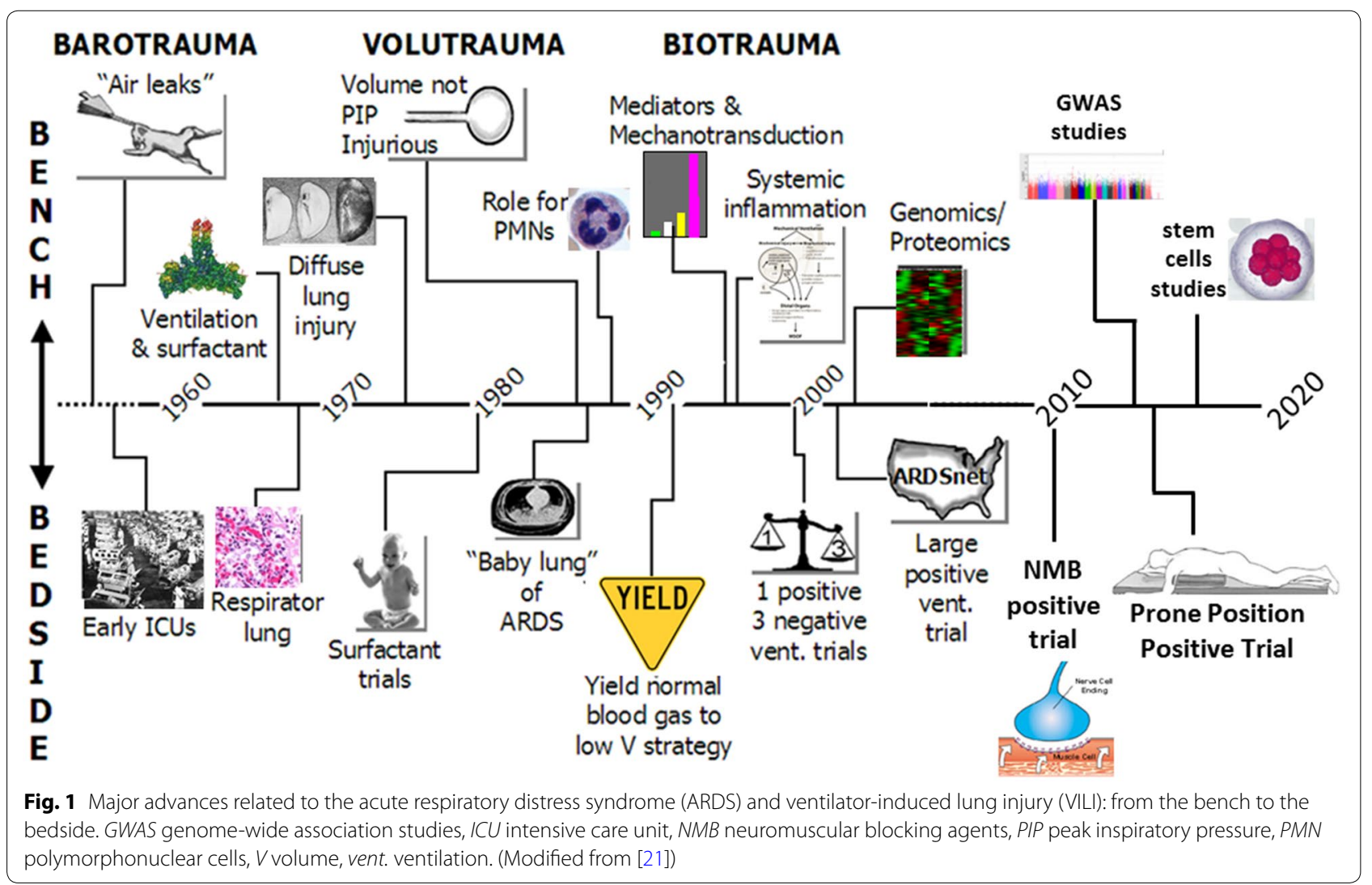

of the lung; however, this "baby" lung must accomplish the entire gas exchange. Overinflation of the most compliant zones which receive the bulk of ventilation can lead to VILI. Injury can also occur by ventilation at low lung volumes [9]. Ashbaugh et al. [2] reported that PEEP improved oxygenation, allowed ventilation with lower $\mathrm{FiO}_{2}$, and probably contributed to higher survival rate. The original rationale for applying PEEP in ARDS was improvement in gas exchange; however, any putative benefit likely arises from its effect on minimizing VILI, since repetitive opening and collapse of unstable lung units causes lung injury due to the stresses placed on the junctional tissue between collapsed and open lung units [9]. Although it is likely that sufficient PEEP should be applied to maintain the lung open (on average $10-16 \mathrm{cmH}_{2} \mathrm{O}$ ), despite decades of research, the optimal way to apply PEEP remains a matter of debate.

What is no longer a matter of debate is the fact that lung-protective ventilatory strategies can improve outcomes in ARDS patients, and likely in patients without ARDS. The seminal contribution in this regard is the ARDSNet study [13] which demonstrated a $9 \%$ absolute mortality reduction by applying a low tidal volume, lungprotective strategy with limitation of plateau pressures.
Over the past decade there have been a number of positive clinical trials [13-17], all of which are based on minimizing VILI (e.g., use of neuromuscular blocking agents [16] and prone ventilation [17]). This contrasts with the past 50 years during which there have been no positive clinical trials of pharmacological agents aimed at the underlying basic mechanisms of lung injury or repair [18]. This likely relates in part to the importance of VILI, but perhaps more importantly to the fact that the definitions of ARDS that we have had are all physiologically based, and hence may not identify the correct targets for pharmacological therapies-again pointing out the importance in identifying suitable biomarkers.

As intensivists, it is incumbent on us to consider not only our patients' short-term outcomes but also the long-term consequences. In this respect, another major advance over the past 20 years has been our increased understanding of the long-term physiology and quality of life of surviving ARDS, as well the psychological stresses on the family members and caregivers of ARDS survivors [19].

Clinicians have long recognized that not all patients with ARDS are alike. It now seems clear that the pathogenesis of most diseases is influenced by the host 
genotype, the environment, and the nature of the underlying injury process. Predisposing genetic factors can interact with the environment to determine the diversity of clinical manifestations, the response to treatment, and outcomes among ARDS patients. Exposing these genetic factors will (hopefully) reveal therapeutic targets and a foundation to predict ARDS susceptibility, and outcomes. Several association studies have been performed in ARDS, mostly focused on specific biological candidate genes, and only recently have explored the entire genome [20]. The search for genetic variants determining susceptibility and predicting outcomes will have an impact on the development of more efficient genotype- and phenotype-guided therapies for ARDS patients over the next 50 years.

\section{Author details \\ ${ }^{1}$ Keenan Research Center for Biomedical Science, Li Ka Shing Knowledge Insti- tute, St. Michael's Hospital, Toronto, ON M5B 1W8, Canada. ${ }^{2}$ Interdepartmental Division of Critical Care Medicine, University of Toronto, Toronto, Canada. ${ }^{3}$ CIBER de Enfermedades Respiratorias, Instituto de Salud Carlos III, Madrid, Spain. ${ }^{4}$ Multidisciplinary Organ Dysfunction Evaluation Research Network, Research Unit, Hospital Universitario de Gran Canaria Dr. Negrín, Las Palmas de Gran Canaria, Las Palmas, Spain. ${ }^{5}$ Fondazione IRCCS Ca' Granda Ospedale Maggiore Policlinico, Milan, Italy. ${ }^{6}$ Dip Fisiopatologia Medico Chirurgica e dei Trapianti, Università di Milano, Milan, Italy.}

\section{Acknowledgments}

This work was supported in part by Canadian Institutes of Health Research, Instituto de Salud Carlos III (CB06/06/1088, PI13/0119) and Asociación Científica Pulmón y Ventilación Mecánica. The funders had no role in the content, decision to publish, or preparation of the manuscript.

\section{Compliance with ethical standards}

\section{Conflicts of interest}

A. Slutsky has received research grants from Canadian Institutes of Health Research (CIHR) and is a consultant for Baxter, Maquet Critical Care, and Xenios. J. Villar has received research grants from Maquet. A. Pesenti has received research grants from Maquet Critical Care and Drager and is a consultant for Xenios and Baxter.

Received: 16 February 2016 Accepted: 18 February 2016

Published online: 14 March 2016

\section{References}

1. Brewer LA III, Burbank B, Samson PC, Schiff CA (1946) The "wet lung" in war casualties. Ann Surg 123:343-362

2. Ashbaugh DG, Bigelow DB, Petty TL, Levine BE (1967) Acute respiratory distress in adults. Lancet 2:319-323

3. Bernard GR, Artigas A, Brigham KL, Carlet J, Falke K, Hudson et al (1994) The American-European consensus conference on ARDS. Am J Respir Crit Care Med 149:818-824
4. Ranieri VM, Rubenfeld GD, Thompson BT, Ferguson ND, Caldwell E, Fan E, Camporota L, Slutsky AS (2012) Acute respiratory distress syndrome: the Berlin definition. JAMA 307:2526-2533

5. Villar J, Pérez-Méndez L, Blanco J, Añón JM, Blanch L, Belda J, SantosBouza A, Fernández RL, Kacmarek RM, Spanish Initiative for Epidemiology, Stratification, and Therapies for ARDS (SIESTA) Network (2013) A universal definition of ARDS: the $\mathrm{PaO}_{2} / \mathrm{FiO}_{2}$ ratio under a standard ventilatory setting - a prospective, multicenter validation study. Intensive Care Med 39:583-592

6. Tomashefski JF Jr (2000) Pulmonary pathology of acute respiratory distress syndrome. Clin Chest Med 21(3):435-466

7. Ware LB, Matthay MA (2000) The acute respiratory distress syndrome. N Engl J Med 342:1334-1349

8. Dreyfuss D, Soler P, Basset G, Saumon G (1988) High inflation pressure pulmonary edema: respective effects of high airway pressure, high tidal volume, and positive end-expiratory pressure. Am Rev Respir Dis 137:1159-1164

9. Slutsky AS, Ranieri VM (2013) Ventilator-induced lung injury. N Engl J Med 369:2126-2136

10. Tremblay L, Valenza F, Ribeiro SP, Li J, Slutsky AS (1997) Injurious ventilatory strategies increase cytokines and c-fos m-RNA expression in an isolated rat lung model. J Clin Invest 99:944-952

11. Villar J, Slutsky AS (2010) Is acute respiratory distress syndrome an iatrogenic disease? Crit Care 14:120

12. Gattinoni L, Pesenti A (2005) The concept of baby lung. Intensive Care Med 31:776-784

13. The ARDS Network (2000) Ventilation with lower tidal volumes as compared with traditional tidal volumes for acute lung injury and the acute respiratory distress syndrome. N Engl J Med 342:1301-1308

14. Villar J, Kacmarek RM, Pérez-Méndez L, Aguirre-Jaime A (2006) A high positive end-expiratory pressure, low tidal volume ventilatory strategy improves outcome in persistent acute respiratory distress syndrome: a randomized, controlled trial. Crit Care Med 34:1311-1318

15. Burns KE, Adhikari NK, Slutsky AS, Guyatt GH, Villar J, Zhang H, Zhou Q, Cook DJ, Stewart TE, Meade MO (2011) Pressure and volume limited ventilation for the ventilatory management of patients with acute lung injury: a systematic review and meta-analysis. PLoS One 6:e14623

16. Papazian L, Forel JM, Gacouin A, Penot-Ragon C, Perrin G, Loundou A, Jaber S, Arnal JM, Perez D, Seghboyan JM, Constantin JM, Courant P, Lefrant JY, Guérin C, Prat G, Morange S, Roch A, ACURASYS Study Investigators (2010) Neuromuscular blockers in early acute respiratory distress syndrome. N Engl J Med 363:1107-1116

17. Guérin C, Reignier J, Richard JC, Beuret P, Gacouin A, Boulain T, Mercier E, Badet M, Mercat A, Baudin O et al (2013) Prone positioning in severe acute respiratory distress syndrome. N Engl J Med 368:2159-2168

18. Tonelli AR, Zein J, Adams J, loannidis JP (2014) Effects of interventions on survival in acute respiratory distress syndrome: an umbrella review of 159 published randomized trials and 29 meta-analyses. Intensive Care Med 40:769-787

19. Herridge MS, Tansey CM, Matté A, Tomlinson G, Diaz-Granados N, Cooper A, Guest CB, Mazer CD, Mehta S, Stewart TE et al (2011) Functional disability 5 years after acute respiratory distress syndrome. N Engl J Med 364:1293-1304

20. Acosta-Herrera M, Pino-Yanes M, Pérez-Méndez L, Villar J, Flores C (2014) Assessing the quality of studies supporting genetic susceptibility and outcomes of ARDS. Front Genet 5:20

21. Tremblay LN, Slutsky AS (2006) Ventilator-induced lung injury: from the bench to the bedside. Intensive Care Med 1(32):24-33 